\title{
Policy Decisions and Response to Fight 2019 Novel Coronavirus Disease in Uganda: A review of Attributes, Comprehensiveness and Implications to Improve Resilience to Future Pandemics
}

Frank Kiwanuka ( $\nabla$ franki@heref.org )

Health Research Facility https://orcid.org/0000-0001-8178-3120

Shafik Waswa

Health Research Facility

Yisak Hagos Alemayehu

Adrigat University of Medicine and Health Sciences, College of Health Sciences, Adrigat, Ethiopia Joel Abrahams Simbeye

Muhimbili National Referral Hospital, Tanzania

\section{Systematic Review}

Keywords: policy, COVID-19, Uganda, Pandemic, epidemic, SARS-CoV-2, coronavirus disease

Posted Date: May 13th, 2020

DOI: https://doi.org/10.21203/rs.3.rs-28670/v1

License: (c) (1) This work is licensed under a Creative Commons Attribution 4.0 International License.

Read Full License 


\section{Abstract}

Uganda experiences recurrent epidemics. However, policies enacted to prevent or prepare for future epidemics remain unclear. This paper reviews policies that are shaping responses to the Coronavirus disease (COVID-19) in Uganda. An integrative systematic review approach using the Preferred Reporting Items for Systematic Reviews and Meta-analysis (PRISMA) was adopted. Databases including organizational websites, bibliographical databases, and newsletters were searched for records on policies addressing response to COVID-19. Quality appraisal was conducted using the von Wright's logic of events framework and the AGREE II (Appraisal of Guidelines, Research and Evaluation) checklist. A descriptive qualitative narrative approach was used for data analysis. Fifteen papers are included in this review. Uganda's preparedness to COVID-19 was initiated before the first case was identified on 21 March 2020. Most documents included in our final analysis were soft policy (nonstatutory) documents $(n=10)$. MoH implemented four public orders: notification of COVID-19; prohibition of entry into Uganda; control of COVID-19; prevention of COVID-19; requirements and conditions of entry into Uganda. In addition, the office of the president implemented three directives as of 08 May 2020; the initial directive included preparatory instructions to the public and ministries before the first case of COVID-19 was registered. Subsequently, three other presidential directives were established; two of these instituted lockdown measures while one instituted the first phase of releasing some lockdown measures. Soft policies identified in this review included guidelines $(n=4)$; press releases $(n=4)$ and mitigation measures. Three out of the four guidelines were clinical practice guidelines, these include quarantine of individuals in the context of containment of COVID-19, COVID-19 preparedness and response plan-laboratory manual, and national guidelines for management of COVID-19 patients.

Conclusion: Uganda has experience built from response to previous epidemics. Uganda has robust policies in place to respond to COVID-19. Comprehensive Policies integrating human capital, research and economical aspects of an epidemic can increase and better prepare Uganda for future.

\section{Introduction}

Wuhan, Hubei Province, China was the first place to report Severe Acute Respiratory SyndromeCoronavirus-2 (SARS-COV-2) which causes the coronavirus disease-2019 (COVID-19) (Nadeem et al., 2020). Since then, the novel coronavirus disease 2019 pandemic has become a major global public health menace. COVID-19 has affected every country in the world, activities of daily living and continues to claim lives daily (Kirigia \& Muthuri, 2020; Ucar \& Korkmaz, 2020). On the $1^{\text {st }}$ May 2020, there were $3,345,203$ confirmed cases, 238,796 deaths, with North America and Europe being the most affects areas. Recently, there is no specific management for COVID-19 (Zhang, Yu, Zhou, Shen, \& Sun, 2020) yet it continues to affect many health systems across the world.

Cross-country followed by community transmission have been the major ways of transmitting COVID; this occurs via intercontinental transport routes such as flights (Gómez-Ríos, Ramirez-Malule, \& RamirezMalule, 2020). Thus, collective response to migratory flow via air, land and sea is essential especially as 
countries continue to release restriction measures. Effective monitoring of areas that are highly infested with COVID-19 is an essential component in the fight against the pandemic (Ucar \& Korkmaz, 2020). However, this might be challenging without a common ground in perspective of cross border movement and trade.

Policies used by different countries are vital to their success in fighting the pandemic. Broader policies in response to epidemics outline the choice of actions that have been taken by different countries and regional blocks. A policy is a law, regulation, procedure, administrative action, incentive or government(s)'/ institutional practice (Karlsson \& Takahashi, 2017). A health policy shapes the health of communities through enabling and limiting certain practices (Gakh, 2019). Policies can be broadly classified into hard (statutory) and soft (nonstatutory) categories. Hard policies are statutorily binding decisions consisting of compulsory requirements (Akkerman \& Torenvlied, 2004). Hard policies emerge out of regulatory and legislative processes; these carry the threat of sanction for noncompliance. Soft policies are voluntary, often nonbinding decisions, guidelines or recommendations based on appeal and attraction emerging from multilevel systems of government that require alternative approaches other than legislation and regulation (Akkerman \& Torenvlied, 2004; Torenvlied \& Akkerman, 2004). Policies have the power to preserve a society's focus on collectively desired goals. Here, policies symbolize a system of connection between partners and/or a way in which certain actions modify others and can be contested. Foucault's theory of power suggests that power relations in societies are informed by culturally engendered notions and that these notions can be accepted or contested (Foucault, 2002). Foucault further asserts that societies are directed by concepts that guide behaviours and such notions constitute policy discourses moderated by social interactions. However, the discursive relational patterns of policy moderation are held by society's powerbrokers, who maintain a grip on the process to sustain the power balance in favour of the prevailing political interests (Ward et al., 2016). Powerbrokers must convince their societies to accept a policy by making it relevant to society's needs, realistic and reflective of collective values and aspirations, and flexible enough to accommodate the changes in an evolving society (Greene, 2014; Ward et al., 2016). Policy elements are reflected through solicitation of ideas from stakeholders in order to make a policy inclusive.

Furthermore, the construct of power is continuously exercised when the policy is approved by an authority. At the community level, where COVID-19 induced effects are most experienced, different coping and adaptation capacities exist. Capacities vary between communities and manifest as common shared values, experiences, connectedness, collective responses, and the ability to learn and share knowledge to overcome adversity (Greene, 2014). The level of community capacity depends on its ability to harness the prevailing resources and on policies that aid collective responses to reduce the effects of COVID-19. Foucault (2002) argued that social interactions inform knowledgeability and influence power relations. He further argued that the balance of power relations resides in a symbiotic duality of recognition and/or maintenance of those over whom power is exercised throughout a process and that the exercise of a power induces reactions that produce the desired change. In the context of our study, the desired change is country policy response to COVID-19 that enhances current and future preparedness to COVID-19 as well as other epidemics. 
Uganda is one of the East African Community (EAC) countries. The EAC consists of five countries: Burundi, Kenya, Rwanda, South Sudan, Tanzania, and Uganda. On the $1^{\text {st }}$ May 2020, there were 1,283 confirmed cases, 39 deaths, with Kenya and Tanzania being the most affected areas (WHO-African Region, 2020). EAC countries are affected by COVID-19 differently based on their resilience capacity. This is reflected in each country's policies and choice of response actions; for instance, not all countries declared emergency measures in the same way. Countries in the EAC block have implemented resolute actions. On $30^{\text {th }}$ March 2020, Uganda implemented a country-wide lockdown. This highlights the existence of differing experiences and interventions to COVID-19. However, strengthening infectious disease prevention, detection and response capabilities is needed for reactive epidemic response and global preparedness for future epidemics (Elmahdawy et al., 2017; Ravi, Snyder, \& Rivers, 2019).

The highest number of initial cases reported in Uganda were imported cases. This trend continues as cross border trade and human movement continue. This necessitates collective response to the pandemic as countries strive to level down restriction measures. Uganda adopted a country-level approach to containing COVID-19 with minimal interactions between states in perspective of managing the pandemic. Trust is a vital tool of effective collaborative endeavors (Ryan, Giles-Vernick, \& Graham, 2019). This has been effective in cooperative response to outbreaks such as Ebola, whether such endeavors have prevailed in the fight against COVID-19 remains unclear yet necessary. Tenuous regional relationships associated with sociopolitical and historical perspectives imped response to epidemics (Ryan et al., 2019). Policies are essential for shaping collective response, common lexicon, exchange of findings, facilitation of diagnosis and management of COVID-19. Policy responses to pandemics are essential for improving resilience of health systems. Policy responses for COVID-19 in Uganda is unclear. This necessitates systematic and reflective description of policies and related real-time incidences. Moreover, urgent need of understanding policy response to COVID-19 in Uganda exists, this is vital for policymakers to steer collaborative and coordinated response to COVID-19 in Uganda and the EAC block. The aim of this paper was to explore and systematically synthesis policy responses to COVID-19 in Uganda, we further discuss the comprehensiveness and Implications to improve resilience to future pandemics.

\section{Materials And Methods}

Design: The integrative review approach (Whittemore \& Knafl, 2005) and the Preferred Reporting Items for Systematic Reviews and Meta-Analysis (PRISMA) (Moher, Liberati, Tetzlaff, Altman, \& PRISMA Group, 2009) were employed in this paper. This was suitable for inclusion of different records and enhancement of data collection, extraction, appraisal and analysis.

Search strategy. In this study, policy was defined as is a law, regulation, procedure, administrative action, incentive or government(s)/ institution' practice (Karlsson \& Takahashi, 2017). This broad definition allowed for inclusion of the following items: intents, action plans, principles, acts, response teams, reports, commitments, guidelines and documents with a stated focus on covid-19 response. For the purpose of this paper, the former items were categorized as policy documents in EAC countries. A policy 
response is a discourse between policymakers who frame policy goals and those who implement a policy (Kamara, Sahle, Agho, \& Renzaho, 2020).

A comprehensive search using a combination of keywords that capture government documents were used (supplementary information I). The keywords included: intents, policy, action plans, principles, acts, response teams, reports, commitments, guidelines and documents with a stated focus on covid-19 response. We searched electronic databases and institutional websites for policy documents published till 05/05/2020. We searched PubMed, Google scholar and websites of ministries (supplementary information I). The database search in Google was done using: "all these words: COVID-19; this exact word or phrase: Uganda; language: English; region: Uganda; last updated anytime; terms appearing anywhere in the page; any file format; advanced search". Seven Pages of google were searched. The final search was done on the $6^{\text {th }}$ May 2020.

Study participants: The geographical scope of this paper was Uganda.

Inclusion and exclusion criteria: Based on the adopted definition of policy, we considered a wide range of policy documents (Table 1). Additional documents were obtained by searching reference lists of the included papers.

Table 1: Inclusion and exclusion criteria 
Government documents such as policies and policy reports, action plans, development plans, drought response plans, strategies, and acts of parliament that relate to COVID-19 response

Documents approved by a government entity
Government documents that do not relate to the subject

Unapproved documents or those approved by nongovernment

entities and/or not approved on behalf of government

Documents not classified as government secrets

Government-classified documents

Documents written in English

Full text available and accessible

Inaccessible policies

Both peer- and grey literature

Reviews, editorials, letters to editors, opinion pieces, and

protocols

Documents from EAC countries (Burundi, Kenya, Rwanda, South Sudan, Tanzania and Uganda).

Government documents from non EAC geographical jurisdictions

Data extraction: data was extracted into a RefWorks database for this project. Data items extracted included author, date, country, policy category, thematic area, policy focus (Table 3). All reviewers reviewed the extracted data and sampled the databases and websites with similar search terms used during the general search strategy. They ascertained that the findings matched and reached common ground.

Quality appraisal: Two authors conducted the quality appraisal of included documents. The von Wright's logic of events framework for quality assessment. The logic of events framework was specifically developed to assess policy documents. The framework has 25 items and seven dimensions that address policy accessibility, background, goals, resources, monitoring and evaluation, public opportunities, and obligations (Cheung, Mirzaei, \& Leeder, 2010). Each item was scored with Yes (1 point) and No (0 point). Cutoffs of: 20/25 (robustly developed policy), 15-19/25 (moderately developed) and 14 or less/25 were classified as insufficiently developed policy documents. Clinical practice guidelines are statements systematically developed to guide policy-related and system-related decision; these were appraised using the AGREE II (Appraisal of Guidelines, Research and Evaluation) checklist (Melisa et al., 2010). 
Data synthesis: A descriptive qualitative narrative approach was adopted owing to the diverse design, aims and purposes of the included documents. This allowed for higher level of analysis. The authors initially read and reread the included papers, then identified themes and extracted meaning units.

\section{Results And Discussion}

Uganda's proximity to and frequent travels to and from other EAC countries faces complex challenges in preventing the novel coronavirus disease-2019. This paper explores and systematically synthesis policy responses to COVID-19 in Uganda, we further discuss the attributes, comprehensiveness and Implications to improve resilience to future pandemics.

Table 2: Timeline of novel COVID-19 response incidents in Uganda and Globally 31.2019-May 06.2020 
Declaration of COVID-19 Case
2020 Mar 21 $1^{\text {st. }}$ Uganda $1^{\text {st }}$ case; Imported from Dubai
2019 Dec 31;

China: 27 cases

from Wuhan, Hubei province reported to WHO

2020 Jan 30:

WHO declares COVID as a

PHEIC.

WHO declares COVID-19 a pandemic
Country preparedness for COVID-19
Chinese ambassador to Uganda meets with $\mathrm{MOH}$ to discuss possibility of imported cases and how best COVID-19 can be prevented from entering Uganda (2020 Feb 03)

Activated border infectious response, started arrival health checks for flights from all countries (2020 Feb 03)

President meets government officials to discuss contingency measures, Presidential directive: ministerial implementation of contingency measures (2020 Feb 05)

First general public alert to embrace prevention measures of COVID-19 infection (2020 Feb 07)

$\mathrm{MOH}$ issues update in a press release on false information on COVID-19 and reiterates prevention measures; (2020 Feb 26); issues do's and don'ts of COVID-19

Policy response: $\mathrm{MOH}$ will screening all travelers; travelers from CHINA will be isolated for 14 days for follow-up; Chinese in Uganda with a travel history cautioned to follow isolation measures; Ugandan business community travelling back from China is urged to adhere to strict rules of isolation to ensure country is safe; Alert on wash hands with soap and water, and report any suspected cases to the nearest health facility; level 4 health travel advisory

CAA air travel alert (2020 Mar 19)

COVID-19 preparedness and response plan-laboratory manual
Implementation of Public Health Emergency measures
2020 Mar 10: MOH Guidelines for safe mass gathering released.

2020 Mar 18: First guidelines and public restriction measures implemented for 32 days; closure of schools, public transport, restrictions on gathering, and other gathering points closed.

2020 Mar 24: statutory instruments-public health (control of COVID-19) Rules, 2020 passed by MOH; Guidelines on preventive measures against COVID-19 in public service issued by ministry in accordance to presidential directive; 
Contact list of DHOs \& District Surveillance Focal Persons

released to the general public

April 2020; $\mathrm{MOH}$ issues Quarantine guidelines version 2;

national guidelines for management of COVID-19

2020 April 14: Presidential directive on Extension of lockdown

for 21 days

2020 May 04; Presidential directive on first phase of opening

the country

2020 May 20; Bank of Uganda, Measures to mitigate

economic impact of COVID-19

2020 May 06 Confirmed (98), Death (0)

Case overview

Other EAC

countries:

Burundi:

Confirmed

(19), Death

(1); Kenya:

Confirmed

(535), Death

(23); Rwanda:

Confirmed

(261), Death

(0);

South Sudan:

Confirmed

(49), Death

(0); Tanzania:

Confirmed

(480), Death

Globally:

Confirmed

$(3,557,235)$,

death $(245,150)$

EAC: East African Community, WHO: World Health Organisation, MOH: Ministry of Health, PHEIC: Public Health Emergency of International Concern; DHO: District Health Officer

Fifteen papers are included in this review (figure 1) and various incidences that shaped response to COVID-19. Table 2 provides insight into the timeline of events that shaped response to COVID-19 in Uganda. Ugandan authorities started preparing for COVID-19 before the first case was registered on the $21^{\text {st }}$ May 2020. This presented Uganda with an opportunity to prepare for the worst scenario, it could also have contributed to the extent of containment of the virus. The first cases of COVID-19 were first reported in Wuhan, Hubei province in China (Lai et al., 2020). Since then, the pace at which governments prepared for COVID-19 notably accounted for the scenarios that each country faced. During the previous decade, Uganda has experienced various outbreaks including Ebola, Marburg, cholera and hepatitis (Englert, 
Kiwanuka, \& Neubauer, 2019; Nanziri et al., 2020; Okello et al., 2019). This could have instilled much experience on how to respond to outbreaks. Given the previous experience of lives claimed by outbreaks, the Ugandan health authorities were particularly cautious about the emerging COVID-19. Various measures were set in place in preparation for the outbreak (Table $2 \& 3$ ). Uganda's frequent trade with China, Dubai and Europe, and the frequency of travelers between Dubai and Uganda created concerns that the virus could soon arrive in Uganda. Indeed, the first cases were identified among returnees from Dubai and China.

Informed by lessons from previous outbreaks, Uganda had systems in place to fight the potential new pandemic. The country has a robust yet poorly functional public health network, a virus research institute and a currently refurbished national referral hospital. However, the country has limited intensive care capacity with only 55 intensive care bed and 15 functional intensive care units (Atumanya et al., 2020). These are very few compared to the population of approximately 40 million people. Uganda will need to expand health financing in order to respond more appropriately to future epidemics.

Critical policy decisions and cross-departmental collaborations happened in preparation for COVID-19 (Table 2). Of note, meeting with representatives of other countries such as the Chinese ambassador offered a glimpse on the experience of COVID-19. This was necessary because travel from China and Europe was the main vehicle for transmission of COVID-19. Thus, cooperation and collaboration were paramount. Devising and updating travels and disease control policies was essential for controlling the transmission of COVID-19. Uganda began health screening of passengers on flights arriving from all over the world. Before the first case of COVID-19, a cross-department taskforce screened all arrivals at Entebbe airport. In addition, media alerts on the prevention of COVID-19 were circulated by ministry of health $(\mathrm{MoH})$. This was essential for alerting the public about what was coming and how to avoid it.

Table 3 provides insight into characteristics of included papers. Policies were mainly designed and instituted by the $\mathrm{MoH}(\mathrm{n}=11)$. Indeed, it is expected that ministries of health take on the lead role in responding to health-related issues. Policy can be broadly categorized into soft and hard categories (Torenvlied \& Akkerman, 2004). Most documents included in our final analysis were soft policy (nonstatutory) documents ( $\mathrm{n}=10$ ), whilst five documents were hard (statutory) policy documents. Torenvlied \& Akkerman, 2004 argue that hard policies are statutory decisions containing compulsory requirements.

\section{Table 3: Included policy category, focus and target in Uganda}




\section{Author, Document Thematic area and title \\ date, \\ country \\ category}

\section{Target group/area}

Ministry Statutory Public health order; Notification General public

of Heath, (hard) policy of COVID-19

2020,

Uganda

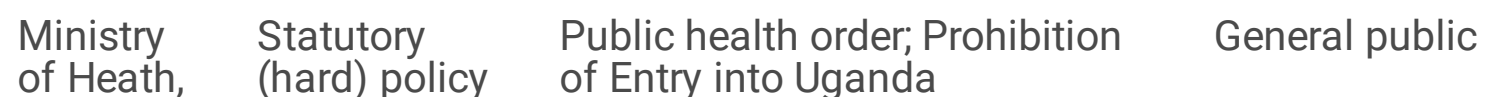

2020,

Uganda

$\begin{array}{lll}\text { Ministry } & \begin{array}{l}\text { Nonstatutory } \\ \text { of Health, }\end{array} & \begin{array}{l}\text { Public health; Do's and don'ts } \\ \text { (soft) policy }\end{array}\end{array} \quad \begin{aligned} & \text { Coronavirus (COVID-19) } \\ & 2020,\end{aligned}$

2020,

Uganda

$\begin{array}{lll}\text { Ministry } & \begin{array}{l}\text { Nonstatutory } \\ \text { of Health, }\end{array} & \text { Press release; No coronavirus in } \\ \text { (solicy } & \text { Uganda }\end{array}$

2020,

Uganda

Ministry Nonstatutory

of Health, (soft) policy

2020,

Uganda

Ministry Statutory

of Health, (hard) policy

2020,

Uganda

Ministry Nonstatutory

of Health, (soft) policy

2020,

Uganda

Office of

the

president,

2020,

Uganda

\section{Ministry Statutory}

of Health, (hard) policy

2020,

Uganda

Uganda Nonstatutory

Civil (soft) policy

Aviation

Authority

\section{Ministry Nonstatutory}

of Health, (soft) policy
Clinical Practice Guidelines;

Guidelines on quarantine of individuals in the context of containment of coronavirus disease (COVID-19) in Uganda

Public health rules; control of

COVID-19
Ministries, departments and

agencies on implementing home, institutional, and geographic quarantine measures for travelers in the context of COVID-19 outbreak.

General public
Public order guidelines: COVID-

19 Guidelines for safe mass gatherings
Organizers of mass gatherings in the context of COVID-19 outbreak.
Presidential directive: guidelines on avoiding the corona virus
General public; educational institutions, public gatherings, travelers from abroad, organization of weddings, funerals, farmers, public transport, hygiene measures

Travelers: examination at port of entry, categorization of persons entering Uganda
Public health Order: Prevention of COVID-19, Requirements and conditions of entry into Uganda
Press release: Aeronautical information service- Outbreak of corona virus (COVID-19) alert
Travelers and aviation industry
Press release: contact list for district health officers \& district surveillance focal persons
General public

Page $11 / 18$ 
2020 ,

Uganda

\begin{tabular}{llll}
$\begin{array}{l}\text { Ministry } \\
\text { of public } \\
\text { service, }\end{array}$ & $\begin{array}{l}\text { Nonstatutory } \\
\text { (soft) policy }\end{array}$ & $\begin{array}{l}\text { Press release: guidelines on } \\
\text { prevention measures against } \\
\text { corona virus (COVID-19) }\end{array}$ & Public service officers \\
\hline & &
\end{tabular}

2020,

Uganda

$\begin{array}{llll}\text { Ministry } & \text { Nonstatutory } & \text { Clinical Guidelines: Coronavirus } & \text { COVID-19 Specimen collectors } \\ \text { of Health, } & \text { (soft) policy } & \begin{array}{l}\text { Disease-2019 (COVID-19) } \\ \text { preparedness and response } \\ \text { 2020, }\end{array} & \begin{array}{l}\text { plan-Laboratory manual } \\ \text { Uganda }\end{array}\end{array}$

\begin{tabular}{|c|c|c|c|}
\hline $\begin{array}{l}\text { Ministry } \\
\text { of Health, } \\
2020\end{array}$ & $\begin{array}{l}\text { Nonstatutory } \\
\text { (soft) policy }\end{array}$ & $\begin{array}{l}\text { Clinical Guidelines: National } \\
\text { guidelines for management of } \\
\text { COVID-19 patients }\end{array}$ & $\begin{array}{l}\text { Medical practitioners-management } \\
\text { of COVID-19 patients }\end{array}$ \\
\hline
\end{tabular}

Uganda

$\begin{array}{lll}\text { Bank of } & \begin{array}{l}\text { Nonstatutory } \\ \text { Uganda, }\end{array} & \text { Economic mitigation measures: } \\ \text { (soft) policy } & \text { Measures to mitigate economic } & \text { Financial sector } \\ \text { 2020, } & & \text { impact of COVID-19 }\end{array}$

Uganda

Adjusting social order remains one of the cardinal measures used in the fight against COVID-19 (Qazi et al., 2020). Maintain such social order requires statutory regulations (hard policy) because without such regulation, abiding to the unusual situation during the COVID-19 era is not feasible. MoH implemented four public orders: notification of COVID-19; Prohibition of entry into Uganda; control of COVID-19, and Prevention of COVID-19, Requirements and conditions of entry into Uganda $(\mathrm{MoH}, 2020)$. In addition, the office of the president implemented three directives as of 08 May 2020; the initial directive was preparatory instructions to the public and ministries before the first case of COVID-19 was registered. Subsequently, three other presidential directives were established; two of these institute lockdown measures while one instituted the first phase of releasing lockdown measures (Table 2). These constituted compulsory requirements that carried the threat of sanction for noncompliance. For instance; acts and presidential directives were instituted in Uganda; these are legal instruments that enable healthcare providers to report suspected cases, and the government to isolate or quarantine persons confirmed or suspected to be infected at designated sites. Table 3 gives insight into the four public health orders and presidential directives inaugurated by $\mathrm{MoH}$ and the President's office.

Soft policies identified in this review included guidelines $(n=4)$; press releases $(n=4)$ and mitigation measures. Three out of the four guidelines were clinical practice guidelines (CPGs): on quarantine of individuals in the context of containment of COVID-19, COVID-19 preparedness and response planlaboratory manual and National guidelines for management of COVID-19 patients ( $\mathrm{MoH}, 2020)$. The CPGs were robustly developed based on our appraisal using the AGREE II quality appraisal tool, based on consensus, all guidelines score above $60 \%$ considering all the six domains of the appraisal tool. Three sets of guidelines on mass gatherings, handline of samples and management of COVID-19 patients 
(Table 3) expanded on the response to COVID-19. The former guidelines highlighted persons allowed for gathering, quarantine procedures, who manages COVID-19 patients and how they should be managed. Quality appraisal of the other policy documents was done using von Wright's logic of events frameworks. These were identified to be insufficiently developed, they lacked clear guidance in the domains of resources, $\mathrm{M} \& \mathrm{E}$, and public opportunities. However, they are accessible and had a clear background, goals and obligations. The economic plans laid by the financial controllers (Bank of Uganda and the parliament) however remain unclear. Response to epidemics requires both health and economic strategies (Fenichel, 2013; Reluga, 2013).

Ugandan authorities need to look beyond health measures to economic response to COVID-19 since majority of the population survive on day to day unsecure employment. Policy decisions also lack preparedness in terms of stockpiling equipment needed to respond to epidemics. Strategies such installation of infrared temperature checkpoints, border quarantine, screening booths, hand sanitizers, stockpiles of personal protective equipment for health workers, predesignated potential isolation wings need to be considered will designing policy decision in response to epidemics (Lin et al., 2020). The Policy responses and strategies in Uganda are lack the former.

Although the enhanced border screening and quarantine procedures led to early detection of cases of COVID-19, strategies on management of quarantine measures need to be expanded to allow people to self-isolate, self-monitor and required to record their temperatures twice daily, stay home or wear a mask if they had to go out. As an extra, the surveillance teams need to call daily or perform checkups by infectious disease staff. Other agencies are also contributing expertise and capacity, these include information technology and cross-department cooperation during the crisis. Since all players are required to submit findings to $\mathrm{MoH}$, a comprehensive database that conveys real time information to clinicians, laboratories and the ministry of health needs to be established. In addition, a customs and immigration database flagging recent travel to highly affected countries within previous countries is essential for future response to outbreaks.

With the outlook of the future of COVID-19 still unclear, clinical and pharmaceutical research capacity and case investigation is inevitable for response to future outbreaks (Lin et al., 2020; Verelst, Kuylen, \& Beutels, 2020). Response to COVID-19 lacks aspects of research. Future response to epidemics requires Uganda to actively participate in the race for finding vaccines and epidemiology of epidemics. University and funded research institutions are required to fulfil this gap. Robust health policies are vital for supporting the exponential need for medical care and testing capacity, the current policies in response to COVID-19 lack a solid distribution infrastructure. This should consist of local health departments and centers staffed with multidisplinary professionals and informed residents especially in rural areas were problems of accessibity are not uncommon. This is required to swiftly respond and coordinate activities.

\section{Conclusion}


This review assessed policy decisions and response to the novel coronavirus disease in Uganda using a systematic review approach. Uganda has experience built from response to previous epidemics. We highlighted soft and hard policy decisions, strengths, weaknesses and gaps that can be prioritized in order to promote and strengthen resilience in the fight against COVID-19. Uganda has robust policies in place to respond to COVID-19. At the same time, Uganda's response to COVID-19 falls short of clinical and pharmaceutical research capacity, case investigation and emergency funding for businesses and the general population. Comprehensive Policies integrating human capital, research and economical aspects of an epidemic can increase and better prepare Uganda for future epidemics. Policymakers must learn from the coronavirus pandemic and create clear operational models for future crises facing the world. EAC countries did not have time, resources and a crisis framework that looks beyond each member's border. Future crises frameworks must integrate joint responses to pandemics among EAC countries.

\section{Declarations}

\section{Data availability}

The search syntax is available as supplementary information I.

\section{Conflict of Interest}

The authors declare no conflict of interests

Funding Statement: This study received no funding from external sources, FK is an early career researcher with funding from the University of Eastern Finland, Kuopio.

\section{References}

Akkerman, A., \& Torenvlied, R. (2004). Theory of" soft" policy implementation in multilevel systems with an application to social partnership in the Netherlands. Acta Politica.

Atumanya, P., Sendagire, C., Wabule, A., Mukisa, J., Ssemogerere, L., Kwizera, A., \& Agaba, P. K. (2020). Assessment of the current capacity of intensive care units in Uganda; A descriptive study. Journal of Critical Care, 55, 95-99. doi:10.1016/j.jcrc.2019.10.019

Brouwers MC, Kho ME, Browman GP, Burgers JS, Cluzeau F, Feder G, Fervers B, Graham ID, Grimshaw J, Hanna SE, Littlejohns P. AGREE II: advancing guideline development, reporting and evaluation in health care. Cmaj. 2010;182(18):E839-42.

Cheung, K. K., Mirzaei, M., \& Leeder, S. (2010). Health policy analysis: a tool to evaluate in policy documents the alignment between policy statements and intended outcomes. Australian health review: a publication of the Australian Hospital Association, 34(4), 405-413. doi:10.1071/AH09767 
Elmahdawy, M., Elsisi, G. H., Carapinha, J., Lamorde, M., Habib, A., Agyie-Baffour, P., ... Usifoh, S. (2017). Ebola virus epidemic in west africa: global health economic challenges, lessons learned, and policy recommendations. Value in Health Regional Issues, 13, 67-70. doi:10.1016/j.vhri.2017.08.003

Englert, E. G., Kiwanuka, R., \& Neubauer, L. C. (2019). When I die, let me be the last. ' Community health worker perspectives on past Ebola and Marburg outbreaks in Uganda. Global Public Health, 14(8), 11821192. doi:10.1080/17441692.2018.1552306

Fenichel, E. P. (2013). Economic considerations for social distancing and behavioral based policies during an epidemic. Journal of Health Economics, 32(2), 440-451. doi:10.1016/j.jhealeco.2013.01.002

Foucault, M. Archaeology of Knowledge, Routledge, London, UK, 2nd edition, 2002.

Gakh, M. (2019). Demystifying Public Health Policy Through Service-Learning Pedagogy. Pedagogy in health promotion, 237337991982949. doi:10.1177/2373379919829499

Gómez-Ríos, D., Ramirez-Malule, D., \& Ramirez-Malule, H. (2020). The effect of uncontrolled travelers and social distancing on the spread of novel coronavirus disease (COVID-19) in Colombia. Travel Medicine and Infectious Disease, 101699. doi:10.1016/j.tmaid.2020.101699

Greene, S. S. (2014). Security program and policies: Principles and practices.

John Hokins University \& Medicine. Coronavirus Resource Center. 2020. Available at: https://coronavirus.jhu.edu/map.html accessed on 02/05/2020

Kamara, J. K., Sahle, B. W., Agho, K. E., \& Renzaho, A. M. N. (2020). Governments' policy response to drought in eswatini and lesotho: A systematic review of the characteristics, comprehensiveness, and quality of existing policies to improve community resilience to drought hazards. Discrete dynamics in nature and society, 2020, 1-17. doi:10.1155/2020/3294614

Karlsson, L. E., \& Takahashi, R. (2017). A Resource for Developing an Evidence Synthesis Report for Policy-Making. Copenhagen: WHO Regional Office for Europe.

Kirigia, J. M., \& Muthuri, R. N. D. K. (2020). The fiscal value of human lives lost from coronavirus disease (COVID-19) in China. BMC Research Notes, 13(1), 198. doi:10.1186/s13104-020-05044-y

Lai, C.-C., Wang, C.-Y., Wang, Y.-H., Hsueh, S.-C., Ko, W.-C., \& Hsueh, P.-R. (2020). Global epidemiology of coronavirus disease 2019 (COVID-19): disease incidence, daily cumulative index, mortality, and their association with country healthcare resources and economic status. International Journal of Antimicrobial Agents, 105946. doi:10.1016/j.jiantimicag.2020.105946

Lin, C., Braund, W. E., Auerbach, J., Chou, J.-H., Teng, J.-H., Tu, P., \& Mullen, J. (2020). Policy decisions and use of information technology to fight 2019 novel coronavirus disease, taiwan. Emerging Infectious Diseases, 26(7). doi:10.3201/eid2607.200574

Page 15/18 
Moher, D., Liberati, A., Tetzlaff, J., Altman, D. G., \& PRISMA Group. (2009). Preferred reporting items for systematic reviews and meta-analyses: the PRISMA statement. Annals of Internal Medicine, 151(4), 2649, W64. doi:10.7326/0003-4819-151-4-200908180-00135

Nadeem, M. S., Zamzami, M. A., Choudhry, H., Murtaza, B. N., Kazmi, I., Ahmad, H., \& Shakoori, A. R. (2020). Origin, Potential Therapeutic Targets and Treatment for Coronavirus Disease (COVID-19). Pathogens (Basel, Switzerland), 9(4). doi:10.3390/pathogens9040307

Nanziri, C., Ario, A. R., Ntono, V., Monje, F., Aliddeki, D. M., Bainomugisha, K., ... Merrill, R. D. (2020). Ebola Virus Disease Preparedness Assessment and Risk Mapping in Uganda, August-September 2018. Health security, 18(2), 105-113. doi:10.1089/hs.2019.0118

Okello, P. E., Bulage, L., Riolexus, A. A., Kadobera, D., Kwesiga, B., Kajumbula, H., ... Zhu, B.P. (2019). A cholera outbreak caused by drinking contaminated river water, Bulambuli District, Eastern Uganda, March 2016. BMC Infectious Diseases, 19(1), 516. doi:10.1186/s12879-019-4036-x

Qazi, A., Qazi, J., Naseer, K., Zeeshan, M., Hardaker, G., Maitama, J. Z., \& Haruna, K. (2020). Analyzing Situational Awareness through Public Opinion to Predict Adoption of Social Distancing Amid Pandemic COVID-19. Journal of Medical Virology. doi:10.1002/jmv.25840

Ravi, S. J., Snyder, M. R., \& Rivers, C. (2019). Review of international efforts to strengthen the global outbreak response system since the 2014-16 West Africa Ebola Epidemic. Health Policy and Planning, 34(1), 47-54. doi:10.1093/heapol/czy102

Reluga, T. C. (2013). Equilibria of an epidemic game with piecewise linear social distancing cost. Bulletin of Mathematical Biology, 75(10), 1961-1984. doi:10.1007/s11538-013-9879-5

Ryan, M. J., Giles-Vernick, T., \& Graham, J. E. (2019). Technologies of trust in epidemic response: openness, reflexivity and accountability during the 2014-2016 Ebola outbreak in West Africa. BMJ Global Health, 4(1), e001272. doi:10.1136/bmjgh-2018-001272

Torenvlied, R., \& Akkerman, A. (2004). Theory of "Soft" Policy Implementation in Multilevel Systems with an Application to Social Partnership in the Netherlands. Acta Politica, 39(1), 31-58. doi:10.1057/palgrave.ap.5500046

Ucar, F., \& Korkmaz, D. (2020). COVIDiagnosis-Net: Deep Bayes-SqueezeNet based diagnosis of the coronavirus disease 2019 (COVID-19) from X-ray images. Medical Hypotheses, 140, 109761. doi:10.1016/j.mehy.2020.109761

Verelst, F., Kuylen, E., \& Beutels, P. (2020). Indications for healthcare surge capacity in European countries facing an exponential increase in coronavirus disease (COVID-19) cases, March 2020. Euro Surveillance, 25(13). doi:10.2807/1560-7917.ES.2020.25.13.2000323 
Ward, S. C., Bagley, C., Lumby, J., Hamilton, T., Woods, P., \& Roberts, A. (2016). What is "policy" and what is "policy response"? An illustrative study of the implementation of the Leadership Standards for Social Justice in Scotland. Educational Management Administration \& Leadership, 44(1), 43-56.

doi:10.1177/1741143214558580

Whittemore, R., \& Knafl, K. (2005). The integrative review: updated methodology. Journal of Advanced Nursing, 52(5), 546-553. doi:10.1111/j.1365-2648.2005.03621.x

World Health Organization-Africa. Coronavirus (COVID-19). Available at: https://www.afro.who.int/healthtopics/coronavirus-covid-19 Accessed on 5.02.2020

Zhang, L., Yu, J., Zhou, Y., Shen, M., \& Sun, L. (2020). Becoming a Faithful Defender: Traditional Chinese Medicine against Coronavirus Disease 2019 (COVID-19). The American Journal of Chinese Medicine, 115. doi:10.1142/S0192415X2050038X

\section{Figures}

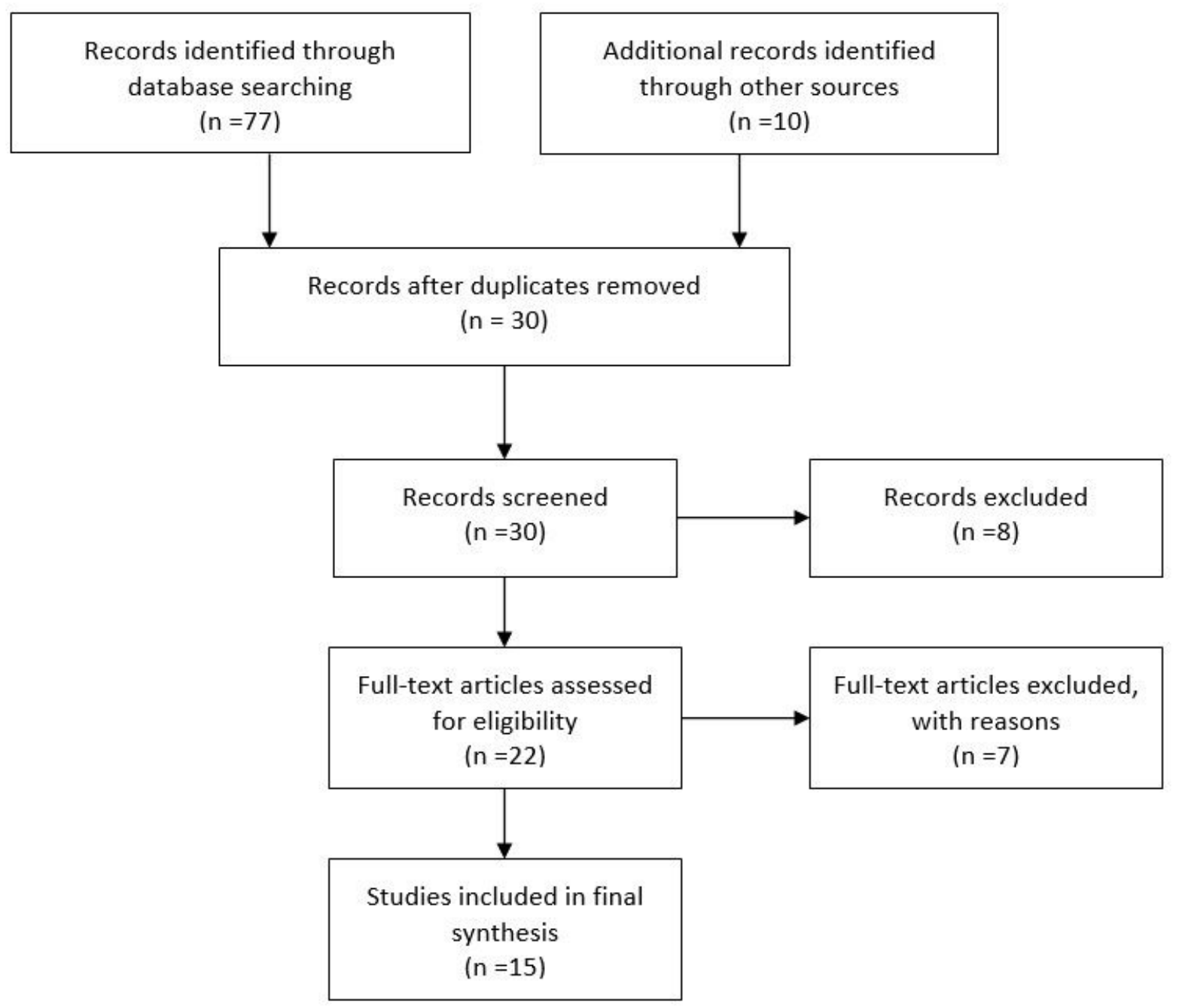


Figure 1

PRISMA flow diagram showing study selection

\section{Supplementary Files}

This is a list of supplementary files associated with this preprint. Click to download.

- SupplementaryInformation1.doc 